\title{
AVALIAÇÃO DA QUALIDADE DO AR INTERIOR DO HOSPITAL UNIVERSITÁRIO PEDRO ERNESTO
}

\author{
Eduardo Delfino Sodré \\ Doutor em Ciências - Biólogo - Laboratório de Radioecologia e Mudanças Globais (LARAMG) - \\ Universidade do Estado do Rio de Janeiro \\ $\checkmark$ delfinosodré@gmail.com \\ João Carlos de Oliveira Tórtora \\ Farmacêutico e Bioquímico - Doutor em Ciências/Microbiologia - Universidade Gama Filho \\ Sergio Machado Corrêa \\ Professor Doutor em Química \\ Faculdade de Tecnologia, Universidade do Estado do Rio de Janeiro UERJ
}

\begin{abstract}
Resumo:
A "Síndrome do Edifício Doente" é um termo utilizado para definir a má qualidade do ar de ambientes interiores e tem sido de preocupação crescente da comunidade científica. A avaliação da qualidade do ar, nos locais amostrados no HUPE, fundamentada na resolução ${ }^{\circ}$ 9 de 2003 da Agência Nacional de Vigilância Sanitária, teve como objetivos conhecer e informar para que a Comissão de Controle de Infecção Hospitalar avalie a interação deste fator com as infecções nosocomiais e decida pela necessidade, ou não, de medidas corretivas e contribuir para o conhecimento e desenvolvimento de técnicas e controle da poluição "Indoor". As amostras foram coletadas com um amostrador de ar tipo impactador linear, de um estágio (MERCK) e a interpretação dos resultados utilizou dois critérios contidos na norma vigente: o valor máximo aceitável (VMA) de fungos em ambientes internos $\left(750 \mathrm{UFC} / \mathrm{m}^{3}\right)$ e o limite aceitável entre a contaminação interna e externa $(\mathrm{I} / \mathrm{E} \leq 1,5)$. Entre os sessenta ambientes avaliados nos três primeiros pavimentos do HUPE 20\% do total encontravam-se em desacordo com relação ao número de $U F C / m^{3}$ e $16,6 \%$ em relação à relação I/E. Conclui-se que $28 \%$ dos setores avaliados do $1^{\circ}$ pavimento do HUPE e $26 \%$ dos contidos no $2^{\circ}$ pavimento não estão tendo a renovação de ar desejada, propiciando o acúmulo de fungos.
\end{abstract}

Palavras-chave: Poluição interior, Síndrome do Edifício Doente.

\section{EVALUATION OF THE INDOOR AIR QUALITY OF UNIVERSITARY HOSPITAL PEDRO ERNESTO}

\begin{abstract}
:
The "Sick Building Syndrome" is a term used to define the poor quality of indoor air environments and has been of growing concern in the scientific community. The assessment of air quality in the places sampled in HUPE, based on Resolution No. 9 of 2003 of the National Health Surveillance Agency, aims to identify and report to the Hospital Infection Control Commission to assess the interaction of this factor with the nosocomial infections and the need to decide whether or not corrective measures and contribute to the knowledge and development techniques and pollution control "Indoor". The samples were collected with an
\end{abstract}


air linear impactor type sampler, a stage (MERCK) and the interpretation of results used two criteria contained in current legislation: the maximum acceptable value (VMA) of fungi in indoor environments $\left(750 \mathrm{UFC} / \mathrm{m}^{3}\right)$ and the acceptable limit between the internal and external contamination $(\mathrm{I} / \mathrm{E} \leq 1.5)$. Among the sixty locations evaluated in the first three floors of HUPE $20 \%$ of the total were in disagreement about the number of $\mathrm{CFU} / \mathrm{m}^{3}$ and $16.6 \%$ compared to I/E ratio. It was concluded that $28 \%$ of the evaluated sectors of the $1^{\text {st }}$ HUPE the floor and $26 \%$ from those in the $2^{\text {nd }}$ floor are not having the desired air change, leading to the accumulation of fungi.

Palavras-chave: Indoor Pollution, Sick Building Syndrome.

\section{INTRODUÇÃO}

O ambiente confinado, local onde passamos a maior parte do nosso tempo, geralmente possui pouca troca de ar com o meio externo e por isso tende a acumular gases e/ou particulados nocivos à saúde. A Organização Mundial de Saúde relatou que a poluição indoor foi responsável, em todo mundo, por mais de 4.300 .000 mortes em 2012 e está ligada a acidente vascular cerebral, doença isquêmica do coração, câncer de pulmão, infecções respiratórias entre outras, WMO (2014).

Nas últimas décadas, a preocupação com a qualidade do ar interior tem aumentado devido a um número crescente de doenças relacionadas a esses ambientes. Um dos casos mais emblemáticos sobre esse tema ocorreu em 1976 em uma convenção da Legião Americana que foi realizada no "Bellevue Stradford Hotel" no estado da Filadélfia nos Estados Unidos e ocorreu o primeiro caso grave de infecção por Legionella pneumophila causando 182 casos de pneumonia e 29 mortes. Atualmente, há uma estimativa de que grande parte das pessoas, principalmente em ambientes urbanos, passe entre 80 e $90 \%$ do seu tempo dentro de edifícios. De acordo com PARKER (1993), isto significa que, na maior parte do tempo, estamos sujeitos a um ambiente artificial que é modificado pelo espaço fechado do edifício e o que é pior, modificado de maneira negativa, já que o problema da qualidade do ar é real e crescente.

O monitoramento da qualidade do ar em ambientes interiores tem se tornado uma prerrogativa fundamental para a manutenção, controle e recuperação da qualidade do ar de ambientes confinados. No mundo inteiro a preocupação com os ambientes confinados veio junto com a crise do petróleo, que em função da economia de energia, impôs ajustes em relação aos sistemas de ar condicionado, reduzindo drasticamente a troca de ar interno/externo de edificações do tipo seladas. "O Instituto Nacional de Segurança Ocupacional e Saúde dos EUA (NIOSH) relata que uma ventilação pobre e inadequada é um fator que contribui de maneira importante em muitos casos de edifícios doentes" (NIOSH, 1994). 


\section{Síndrome do Edifício Doente}

A Organização Mundial de Saúde (OMS) classificou como "Síndrome do Edifício Doente (SED)", uma série de sintomas gerais, que epidemiologicamente afetam ocupantes de um ambiente fechado sem origens determinadas e que, quando os queixosos são afastados do ambiente, apresentam melhoras espontâneas dos sintomas, CARMO e COLS (1999).

\section{Doença de Ambiente Interno (DAI)}

Segundo HANSEN e COLS. (1991) o crescente número de agravos a saúde humana, mesmo não atendendo os critérios epidemiológicos da SED, culminaram com a definição da "Doença de Ambiente Interno" (DAI - Building Related Illness), como um estado mórbido ligado às condições do ambiente interno. Estas sintomatologias podem estar ligadas a poluentes de ordem física, química ou biológica, isolada ou associadamente, promovendo graves quadros clínicos, bem como sequelas, frequentemente presentes entre as pessoas agredidas.

Existe uma diferença muito sutil entre os dois termos utilizados (SED e DAI). Um edifício que possui a "SED" não provoca doenças, ele colabora no sentido de agravar males de pessoas predispostas ou, como já mencionado, de provocar um estado transitório em algumas pessoas. Uma pessoa asmática, por exemplo, ao entrar em um edifício doente, provavelmente sentirá uma irritação no sistema respiratório enquanto permanecer no local. Já edifícios que possuam a "DAÍ", podem provocar doenças, tais como: asma, infecções bacterianas, virais ou por fungos. Estas doenças estão diretamente relacionadas às condições do edifício.

\section{Qualidade do Ar Interior no Brasil}

Segundo RADLER (2003), no Brasil são poucos registros relacionando QAI e SED. Porém, a tendência em se construir prédios selados resulta na preocupação com a climatização, estética e ruído, obrigando a utilização de um sistema de ar condicionado central.

No Brasil, várias iniciativas foram tomadas com o objetivo de estabelecer critérios para a qualidade do ar de ambientes climatizados desde a morte do Ministro Sergio Mota que contraiu uma infecção pulmonar supostamente de um ambiente climatizado. O Ministério da 
Saúde publicou em 1998, a Portaria 3523, contendo Regulamento Técnico que visa "promover o estabelecimento de medidas referentes à limpeza dos sistemas de climatização e medidas específicas de padrões da qualidade do ar, identificando poluentes de natureza física, química e biológica com suas respectivas fontes, visando à prevenção de riscos à saúde dos ocupantes desses ambientes".

A ANVISA (BRASIL, 2000), em função da Portaria 3523, publicou a Resolução 176 de 24 de outubro de 2000, com algumas orientações técnicas sobre "Padrões referenciais da qualidade do ar de interiores em ambientes climatizados artificialmente de uso público e coletivo" e posteriormente uma revisão, a resolução N$^{\circ} 9$ de 16 de janeiro de 2003 (BRASIL, 2003). A resolução define parâmetros para concentração de $\mathrm{CO}_{2}$, material particulado, temperatura, umidade relativa e velocidade do ar em ambientes climatizados.

\section{Estudos de caso}

Li (2014) estudou os constituintes microbiológicos do ar de ambientes confinados e concluiu que $67,73 \%$ eram cocos gram positivos, $24,26 \%$ eram bastonetes gram positivos e 7,10 \% eram bacilos gram negativos. Entre os gêneros identificados estão o Kytococcus sp., Micrococcus sp., Staphylococcus sp., Leifsonia sp., Bacillus sp. e Corynebacterium sp., os quais predominaram no ar interior. As espécies bacterianas mais dominantes foram Kytococcus sedentarius, Staphylococcus epidermidis e Micrococcus luteus. O patógeno oportunista e nosocomial, Stenotrophomonas maltophilia também foi descoberto em um percentual elevado.

Segundo PELCZAR e COLS. (1981) o grau de contaminação do ar interno é influenciado por fatores, tais como as taxas de ventilação, o número de pessoas que ocupam o ambiente, a natureza e o grau de atividade exercida por esses indivíduos.

Como componentes biológicos do ar em ambientes internos, aclimatados artificialmente, KULCSAR NETO \& SIQUEIRA (1998) citam os microorganismos como cohabitantes, apresentando-se em curva exponencial de crescimento. Os autores mostram que há prevalência de bactérias scomo: Legionella pneumophila, Bacillus sp., Flavobacterium sp., Pseudomonas aeruginosa, Staphylococcus aureus, Mycobacterium tuberculosis, Neisseria meningitidis, Streptococcus pneumoniae e Actinomyces thermophilia, e de fungos, como: Paracoccidioides brasiliensis, Histoplasma capsulatum, Cephalosporium sp., Aspergillus sp., Penicillium sp., Cladosporium sp. e Fusarium sp.. 
EZEONU e COLS. (1994) contaminaram com fungos, em laboratório, materiais de isolamento acústico e fibra de vidro térmica usados no aquecimento, ventilação e sistemas de ar condicionados. A mistura de fungos, principalmente Aspergillus versicolor, Acremonium obclavatum e Cladosporium herbarum produziu odores voláteis, incluindo 2-etil hexanol, ciclohexano, e benzeno. Segundo o autor, o benzeno é classificado como um composto químico perigoso pela "Environmental Protection Agency" e "Occupational Safety and Health Administration". O ciclohexano e 2-etil hexanol são conhecidos como irritantes dos olhos e da pele. Este estudo demonstrou que fungos nos sistemas de aquecimento, ventilação e ar condicionado podem desempenhar um papel significativo nos problemas de saúde nos ocupantes de edifícios com essas características.

ANGULO-ROMERO e COLS.(1996) estudaram a presença de fungos no ar interno de doze escolas na Espanha durante dois anos. Foram coletadas 456 amostras usando um aspirador de pó e analisadas para cultura de fungos. Das colônias isoladas 38 \% pertenciam a patogênicos capazes de causar infecções ou doenças de hipersensibilidade. Dos 91 gêneros identificados, os mais frequentes foram: Alternaria, Aspergillus e várias espécies de Penicillium. Os autores observaram também que a maioria destes fungos apresentou variações sazonais na concentração, a qual foi mais abundante entre os meses de abril e outubro.

DE WEI LI e COLS. (1996) fizeram um estudo sobre a relação funcional e causal de contaminação por fungos entre o ar interno e externo em Waterloo, no Canada. Constataram que entre maio e outubro a relação entre o ar interior e exterior foi muito forte, particularmente para Alternaria e Leptosphaeria.

\section{O Hospital Pedro Ernesto (HUPE)}

O Hospital Universitário Pedro Ernesto é um dos maiores hospitais públicos de referência do Rio de Janeiro com uma cobertura assistencial de aproximadamente 1.000.000 (um milhão) de habitantes. Possui cerca de $44.000 \mathrm{~m}^{2}$ de área construída, onde funcionam 600 leitos e 16 salas cirúrgicas e são realizadas internações e cirurgias em mais de 60 especialidades e subespecialidades da área médica.

O HUPE foi inaugurado em 1950, fazendo parte da rede hospitalar da Secretaria de Saúde do então Distrito Federal. Em 1962, tornou-se o Hospital-Escola da Faculdade de Ciências Médicas da Universidade do Estado da Guanabara (UEG), atual Universidade do Estado do Rio de Janeiro (UERJ). No ano de 1965, foi incorporado a (UEG) como Hospital 
das Clínicas. Até então, suas atividades privilegiavam exclusivamente as questões acadêmicas de ensino e pesquisa, com o acompanhamento e estudo de raridades clínicas e doenças em estágio final de evolução. Em 1975, em decorrência do convênio firmado com o Ministério da Educação e Previdência Social (Convênio MEC-MPAS), o HUPE adequou suas atividades para atender a realidade sanitária da população.

\section{Especialidades:}

Enfermaria de Adolescentes Professor Aloysio Amâncio; Núcleo de atenção ao Idoso (NAI); Clínica da Dor; Clínica de Hipertensão do Laboratório de Fisiopatologia Clínica e Experimental (CLINEX); Núcleo de Estudo do Adolescente (NESSA).

Esse estudo teve por finalidade avaliar através de parâmetros microbiológicos qualitativo e relativo (SBMAQAI, 1998) a qualidade do ar do Hospital Universitário Pedro Ernesto, com base na Resolução RE No 9 de 16 de janeiro de 2003 (BRASIL, 2003). Esta resolução estabeleceu critérios para monitoramento da qualidade do ar interior em ambientes climatizados artificialmente, definindo a identificação das fontes poluentes de natureza biológica, química e física, e os métodos analíticos, além de recomendações para controle. Para padrões biológicos foi estabelecido o limite máximo de 750 unidades formadoras de colônias por $\mathrm{m}^{3}$ (UFC/ $\mathrm{m}^{3}$ ) para fungos, desde que não ocorram espécies patogênicas e toxigênicas.

\section{METODOLOGIA/ MATERIAL E MÉTODOS}

A norma técnica ${ }^{\circ} 1$ da Resolução $n^{\circ} 9$ da Agência Nacional de Vigilância Sanitária foi utilizada para a avaliação da qualidade do ar utilizando a contagem de fungos viáveis como marcador epedemiológico como transcrito abaixo:

Método de amostragem: Foi utilizado amostrador de ar por impactação com acelerador linear.

Embalagem: rotina de embalagem para proteção da amostra com nível de biossegurança 2 (recipiente lacrado, devidamente identificado com símbolo de risco biológico). 
Transporte: Rotina de embalagem para proteção da amostra com nível de biossegurança 2 (recipiente lacrado, devidamente identificado com símbolo de risco biológico).

$$
\begin{gathered}
\text { Exatidão: } \pm \text { 0,02 1/min. } \\
\text { Precisão: } \pm \text { 99,92\% }
\end{gathered}
$$

Estratégia de amostragem: Foram coletadas amostras de ar exterior próximo da estrutura predial na altura de 1,50 m do nível da rua. O número de amostras de ar interior, foi tomado, tendo-se por base a área construída climatizada dentro de uma mesma edificação e razão social, seguindo a tabela abaixo:

Tabela 1 - Área construída $\left(\mathrm{m}^{2}\right)$ Número mínimo de amostras

\begin{tabular}{cc}
\hline Área $\left(\mathrm{m}^{2}\right)$ & Número de amostras \\
\hline Até 1.000 & 1 \\
1.000 a 2.000 & 5 \\
2.000 a 3.000 & 8 \\
3.000 a 5.000 & 12 \\
5.000 a 10.000 & 15 \\
10.000 a 15.000 & 18 \\
15.000 a 20.000 & 21 \\
\hline
\end{tabular}

As unidades funcionais do HUPE com características epidemiológicas diferenciadas tais como serviço médico, restaurantes, creches e outros, foram amostradas isoladamente. Os pontos amostrais foram distribuídos uniformemente e coletados com o amostrador localizado na altura de 1,5 m do piso, no centro do ambiente ou em zona ocupada. 
Procedimento Laboratorial: método de cultivo e quantificação segundo normatizações universalizadas. Tempo mínimo de incubação de 7 dias a $25{ }^{\circ} \mathrm{C}$., permitindo o total crescimento dos fungos.

Foi utilizado neste trabalho o amostrador de ar de fabricação MERCK denominado MAS-100, que é um aparelho tipo impactador, com aceleração linear de um estágio que aspira o ar através de uma placa perfurada. $\mathrm{O}$ ar aspirado contém as partículas presentes e atinge diretamente a superfície de uma placa de Petri com meio de cultura adequado.

Especificação técnica do amostrador: Velocidade de fluxo - 100 litros/min. Peso - 2.2 $\mathrm{kg}$.

Figura 1 - Amostrador de ar Merck MAS 100

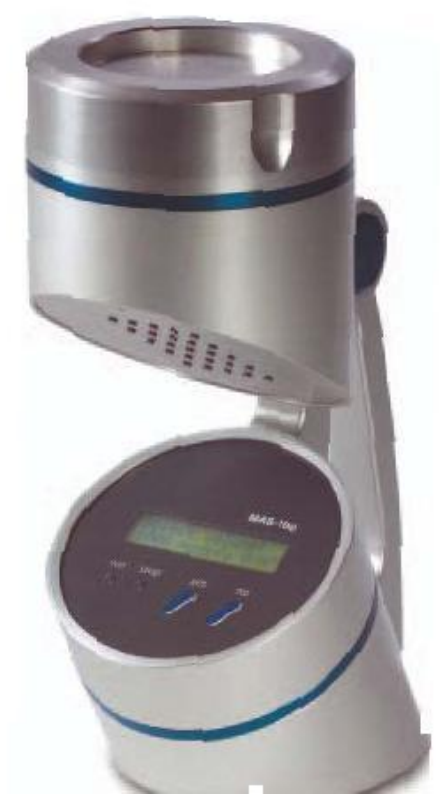

Fonte: PRÓ-ANÁLISE, 2014.

Foi utilizado para este trabalho um volume total de ar de 140L de ar por placa. Meio de cultura utilizado: agar Saboraud para fungos totais. As placas foram incubadas em estufa à $25^{\circ} \mathrm{C}$ por 7 dias, quando foram contadas as unidades formadoras de colônias ( $\mathrm{UFC} / \mathrm{m}^{3}$ ). Após a contagem das UFCs de cada placa foi utilizado uma tabela de conversão de abertura positiva, cedida pelo frabricante do equipamento de amostragem. A tabela é baseada no princípio de que o aumento do número de partículas viáveis atingindo a placa diminui a probablidade da próxima partícula cair em um espaço vazio. Os valores da tabela foram calculados da formula básica de FELLER (1950), onde: $\operatorname{Pr}=$ probabilidade total; $r$ = número de unidades formadoras de colónias Formula $-\operatorname{Pr}=\mathrm{N}[1 / \mathrm{N}+1 / \mathrm{N}-1+1 / \mathrm{N}-2+1 / \mathrm{N}-\mathrm{r}+1]$ 


\section{RESULTADOS}

Estão apresentadas em formas de tabelas e gráficos os resultados da análise quantitativa de colônias de fungos encontradas diversos ambiente do Hospital Pedro Ernesto, UERJ em 2005. Foram analisadas amostras em três pavimentos do HUPE, a saber: $1^{\circ}$ pavimento o ou térreo, $2^{\circ}$ e $3^{\circ}$ pavimentos. As tabelas apresentadas destacam em negrito os locais onde os valores referenciais por UFC (unidades formadoras de colônias) ou I/E\ (razão entre valores de UFC do ar interno e externo) foram ultrapassados.

Tabela 2 - Qualidade Microbiológica do Ar Exterior

\begin{tabular}{ccc}
\hline Amostra de ar externo & $\mathrm{UFC}^{3} \mathrm{~m}^{3}$ & $\mathrm{I} / \mathrm{E} \leq 1,5$ \\
\hline $\mathbf{1 P 1 9}$ & $\mathbf{5 9 3}$ & $\mathbf{1}$ \\
\hline
\end{tabular}

A tabela 2 apresenta o valor referencial de $\mathrm{UFC} / \mathrm{m}^{3}$ do ar externo onde em nenhuma amostra interna deverá ultrapassar 1,5 desse valor ou seja: $889 \mathrm{UFC} / \mathrm{m}^{3}$.

\section{$\mathbf{1}^{\circ}$ pavimento}

Tabela 3 - Qualidade Microbiológica do Ar Interior das Salas do $1^{\circ}$ Pavimento do Hupe

\begin{tabular}{ccc}
\hline $\mathbf{1}^{\circ}$ PAVIMENTO & $\mathbf{U F C}^{\mathbf{3}} \mathbf{3}$ & $\mathbf{I} / \mathbf{E} \leq \mathbf{1 , 5}$ \\
\hline Laboratório de Bacteriologia & 93 & 0,156 \\
Laboratório de Parasitologia & 385 & 0,649 \\
Laboratório de Imunologia & $\mathbf{1 8 6 4}$ & $\mathbf{3 , 1 4 3}$ \\
Laboratório de Endocrinologia & $\mathbf{1 3 6 4}$ & $\mathbf{2 , 3}$ \\
Laboratório de Medicina Nuclear & 264 & 0,445 \\
Laboratório Geral & 50 & 0,084 \\
Corredor 1 ( em frente aos laboratórios) & 207 & 0,349 \\
Laboratório de Micobactérias & $\mathbf{8 2 9}$ & 1,397 \\
Ambulatório de Quimioterapia & $\mathbf{3 6 2 9}$ & $\mathbf{6 , 1 1 9}$ \\
Ambulatório de Pediatria & 114 & 0,192
\end{tabular}




\begin{tabular}{ccc} 
Ambulatório de neurologia & 50 & 0,084 \\
Ambulatório pré-natal & 200 & 0,337 \\
Cozinha & 529 & 0,892 \\
Sala da Nutrição & 229 & 0,386 \\
Farmácia de manipulação & 107 & 0,18 \\
Nutrição Parenteral & 71 & 0,119 \\
Portaria principal & 186 & 0,313 \\
Corredor 2 (Próximo do elevador) & $\mathbf{1 0 1 4}$ & $\mathbf{1 , 7 0 9}$ \\
\hline
\end{tabular}

Gráfico 1 - Percentagem dos Locais Amostrados no Primeiro Pavimento em Função do Valor Máximo Aceitavel $\left(\mathrm{VMA}=750 \mathrm{UFC} / \mathrm{M}^{3}\right)$

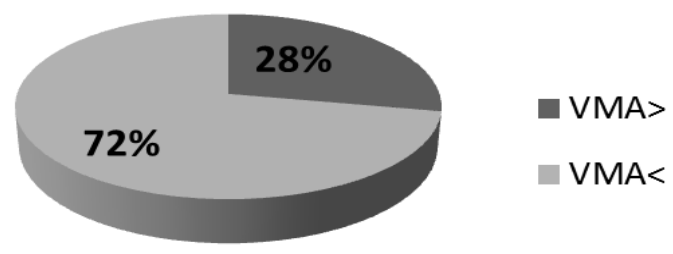

Gráfico 2 - Qualidade Microbiológica do Ar Interno das Salas do $1^{\circ}$ Pavimento do Hupe Avaliada Através de UFC/m

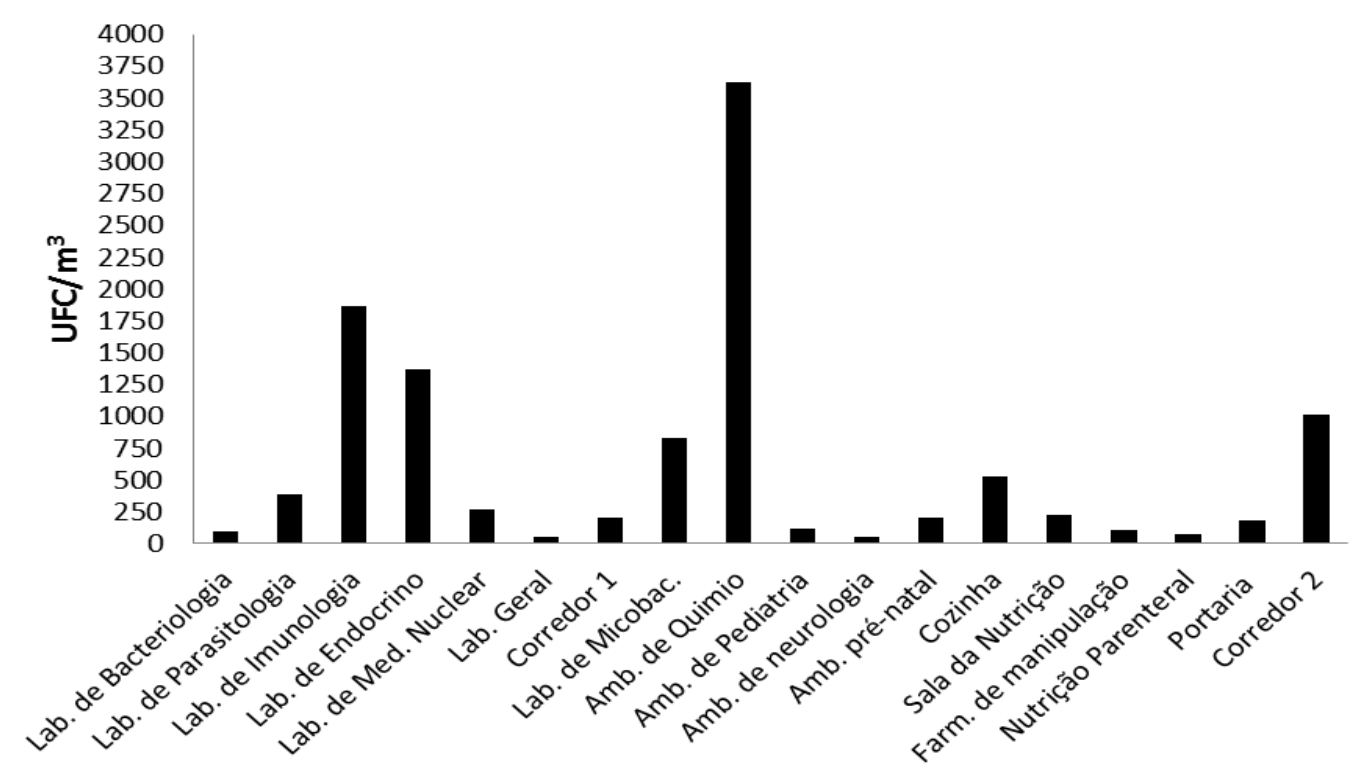


Gráfico 3 - Qualidade Microbiológica do Ar Interno das Salas do $1^{\circ}$ Pavimento do Hupe Avaliada Através da Relação do Ar Interno e Externo

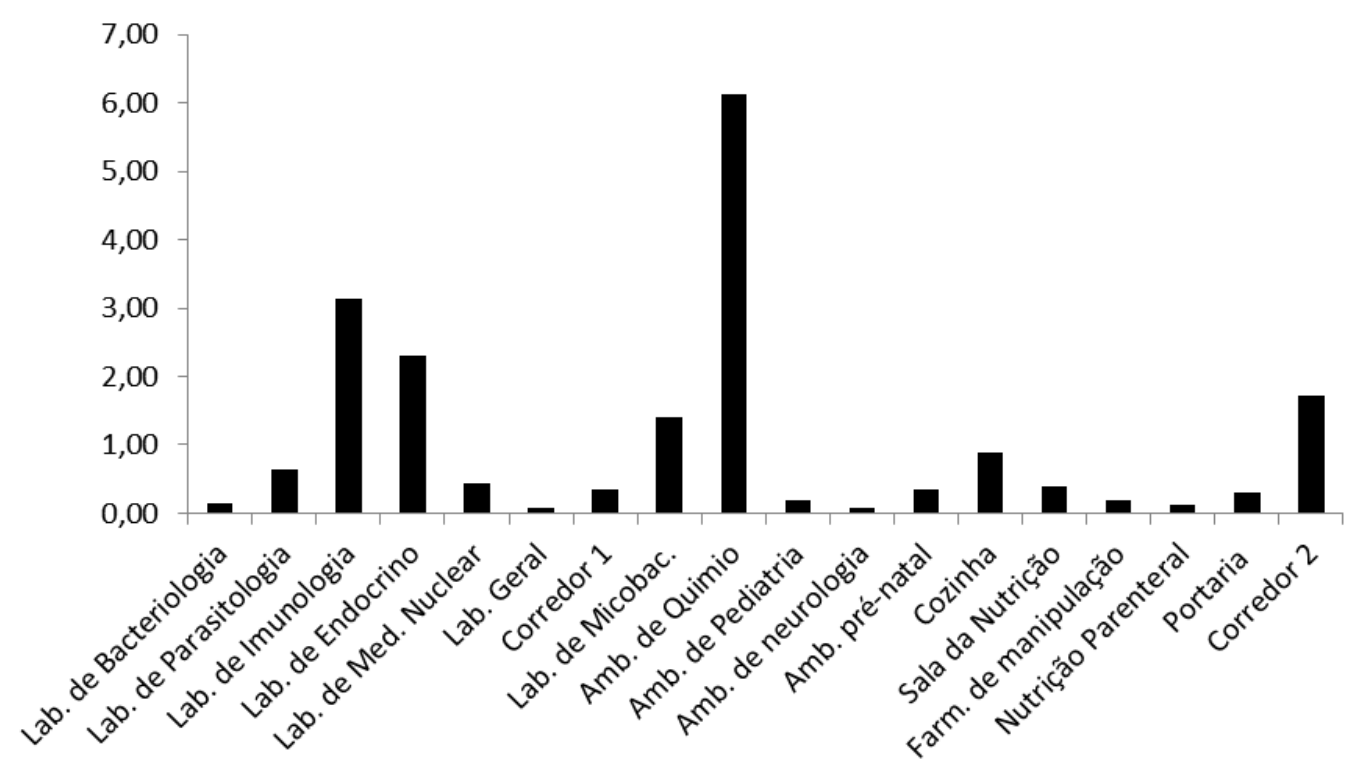

\section{$2^{\circ}$ pavimento}

Tabela 4 - Qualidade Microbiológica do Ar Interior das Salas Do $2^{\circ}$ Pavimento do Hupe

\begin{tabular}{ccc}
\hline $\mathbf{2}^{\circ}$ PAVIMENTO & UFC/m & I/E $\leq \mathbf{1 . 5}$ \\
\hline Enfermaria da pneumologia feminina & 464 & 0,782 \\
Enfermaria da pneumologia masculina & 429 & 0,723 \\
Lab. de prova de função respiratória & 207 & 0,349 \\
Sala de broncoscopia & 207 & 0,349 \\
Sala de fisioterapia respiratória & $\mathbf{1 1 0 0}$ & $\mathbf{1 , 8 5 4}$ \\
Sala de escarro induzido & $\mathbf{1 7 0 7}$ & $\mathbf{2 , 8 7 8}$ \\
Comando de enfermagem da DIP & $\mathbf{1 2 7 1}$ & $\mathbf{2 , 1 4 3}$ \\
Enfermaria da DIP & $\mathbf{1 0 1 4}$ & $\mathbf{1 , 7 0 9}$ \\
Enfermagem feminina da cardiologia & $\mathbf{1 4 0 7}$ & $\mathbf{2 , 3 0 6}$ \\
Enfermaria cardiologia masculino & 564 & 0,951 \\
Sala de procedimentos (pediatria) & 300 & 0,505 \\
Enfermaria pediátrica & 286 & 0,482 \\
Hall da pediatria & 214 & 0,360
\end{tabular}




\begin{tabular}{ccc} 
Lactário & $\mathbf{1 1 0 0}$ & $\mathbf{1 , 8 5 4}$ \\
Laboratório Dermatologia & 279 & 0,470 \\
Laboratório de Micologia & 186 & 0,313 \\
Enfermaria dermatologia masculina & $\mathbf{8 5 7}$ & $\mathbf{1 , 4 4 5}$ \\
Enfermaria dermatologia feminina & 679 & $\mathbf{1 , 1 4 5}$ \\
Cirurgia pediátrica & 43 & 0,072 \\
Sala de Eletroneuromiografia & 186 & 0,313 \\
Enfermaria neurologia feminina & 307 & 0,517 \\
Enfermaria neurologia masculina & 336 & 0,566 \\
Corredor da dermatologia & 314 & 0,529 \\
Corredor da pediatria & 193 & 0,325 \\
Nutrição enteral & 71 & 0,119 \\
Ambulatório de nutrição & 114 & 0,192 \\
Corredor da nutrição & 186 & 0,313 \\
\hline
\end{tabular}

Gráfico 4 - Percentagem dos Locais Amostrados no Segundo Pavimento em Função do Valor Máximo Aceitável $\left(\mathrm{Vma}=750 \mathrm{UFC} / \mathrm{m}^{3}\right)$

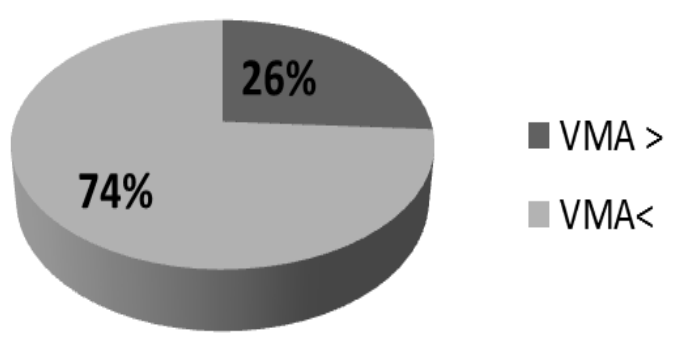


Gráfico 5 - Qualidade Microbiológica do Ar Interno Das Salas do $2^{\circ}$ Pavimento do Hupe Avaliada Através de UFC/ $\mathrm{m}^{3}$

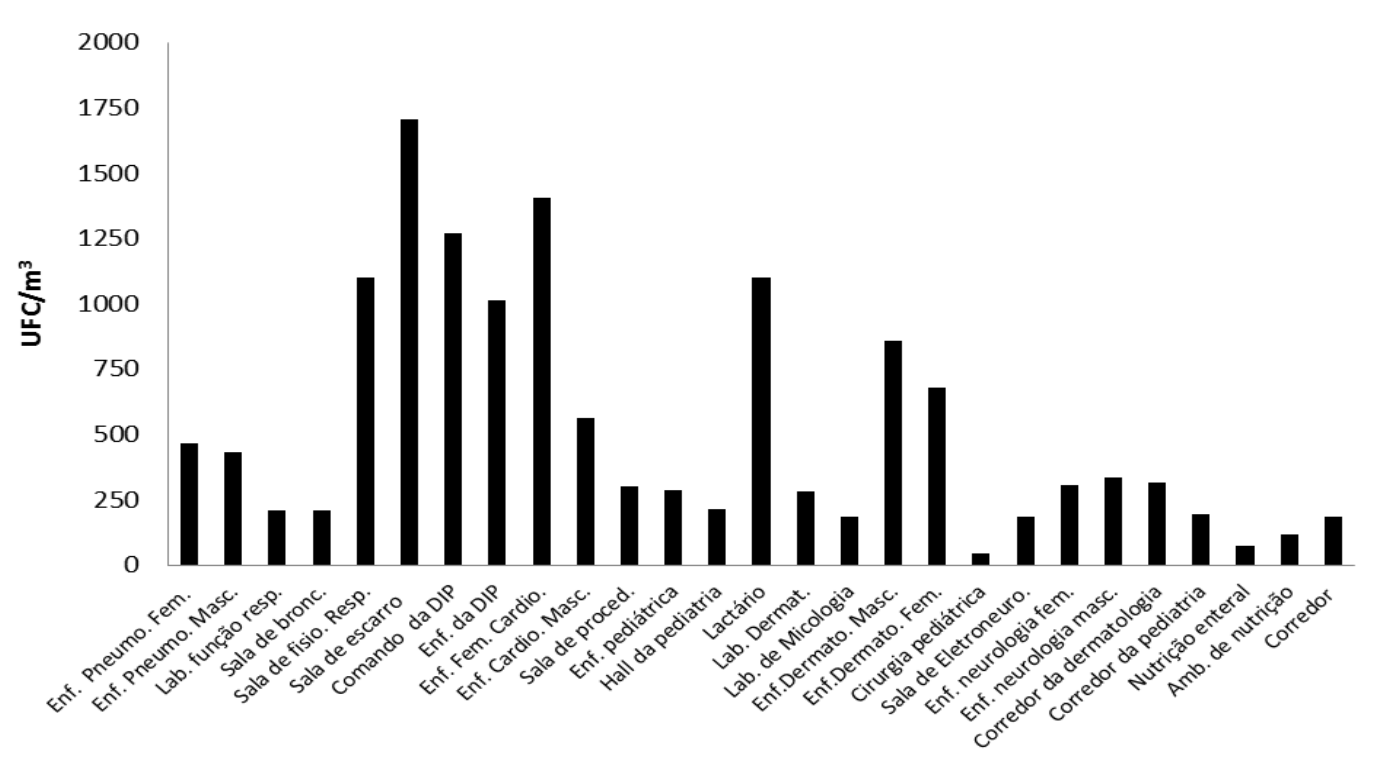

Gráfico 6 - Qualidade Microbiológica do Ar Interno eas Salas do $2^{\circ}$ Pavimento do Hupe Avaliada Através da Relação do Ar Interno e Externo.

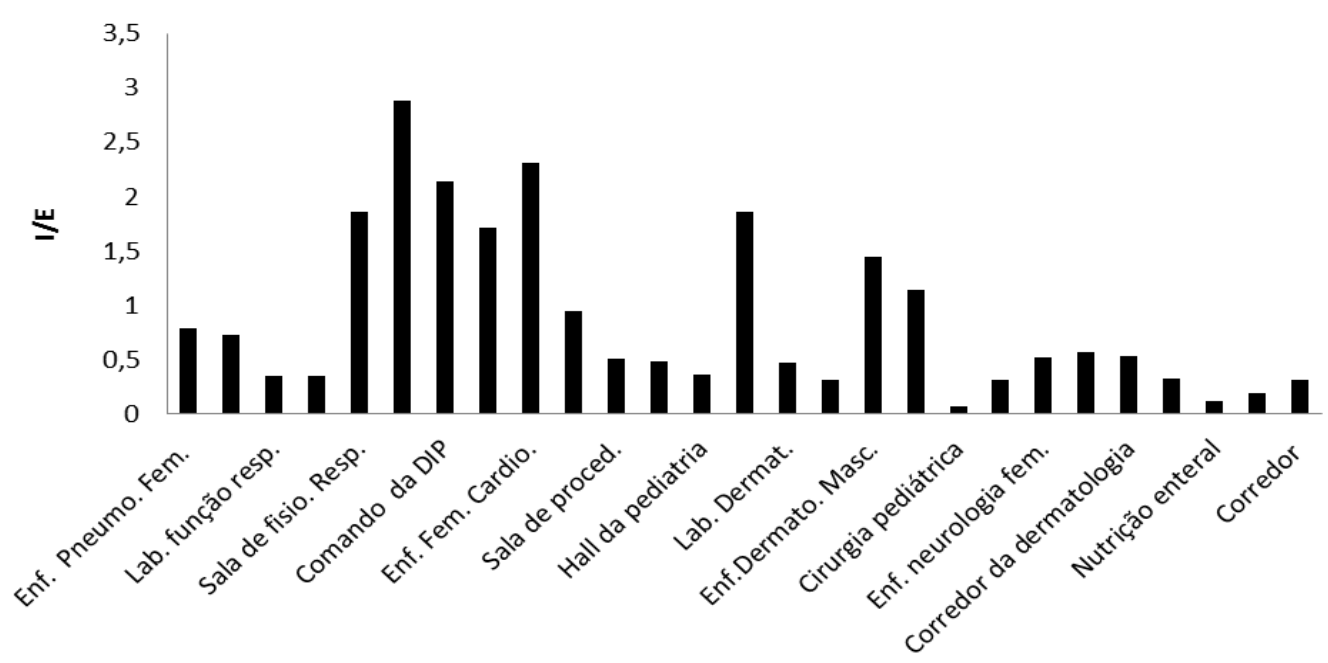




\section{$3^{0}$ pavimento}

Tabela 5 - Qualidade Microbiológica Do Ar Interior Das Salas Do $3^{\circ}$ Pavimento Do Hupe

\begin{tabular}{ccc}
\hline $\mathbf{3}^{\circ} \mathbf{P A V I M E N T O}$ & $\mathrm{UFC} / \mathrm{m}^{3}$ & $\mathrm{I} / \mathrm{E} \leq 1,5$ \\
\hline Laboratório de hematologia & 214 & 0,36 \\
Isolamento da hematologia & 236 & 0,397 \\
Enfermaria da hematologia masculina & 307 & 0,517 \\
Enfermaria da hematologia feminina & 557 & 0,939 \\
Sala de hemodiálise & 229 & 0,386 \\
Enfermaria da nefrologia & 243 & 0,409 \\
Isolamento (1) nefrologia & 164 & 0,276 \\
Isolamento (2) nefrologia & 136 & 0,229 \\
Sala de diálise peritonial & 386 & 0,650 \\
Corredor perto da propedêutica & 636 & 1,07 \\
Corredor perto do elevador & 314 & 0,529 \\
Corredor da colonoscopia & 464 & 0,782 \\
Sala da recreação (UCDA) & 500 & 0,843 \\
Enfermaria (UCDA) & 593 & 1 \\
Posto de enfermagem (UCDA) & 357 & 0,602 \\
\hline
\end{tabular}

Gráfico 7 - Qualidade Microbiológica do Ar Interno das Salas do $3^{\circ}$ Pavimento do Hupe Avaliada Através de UFC/m

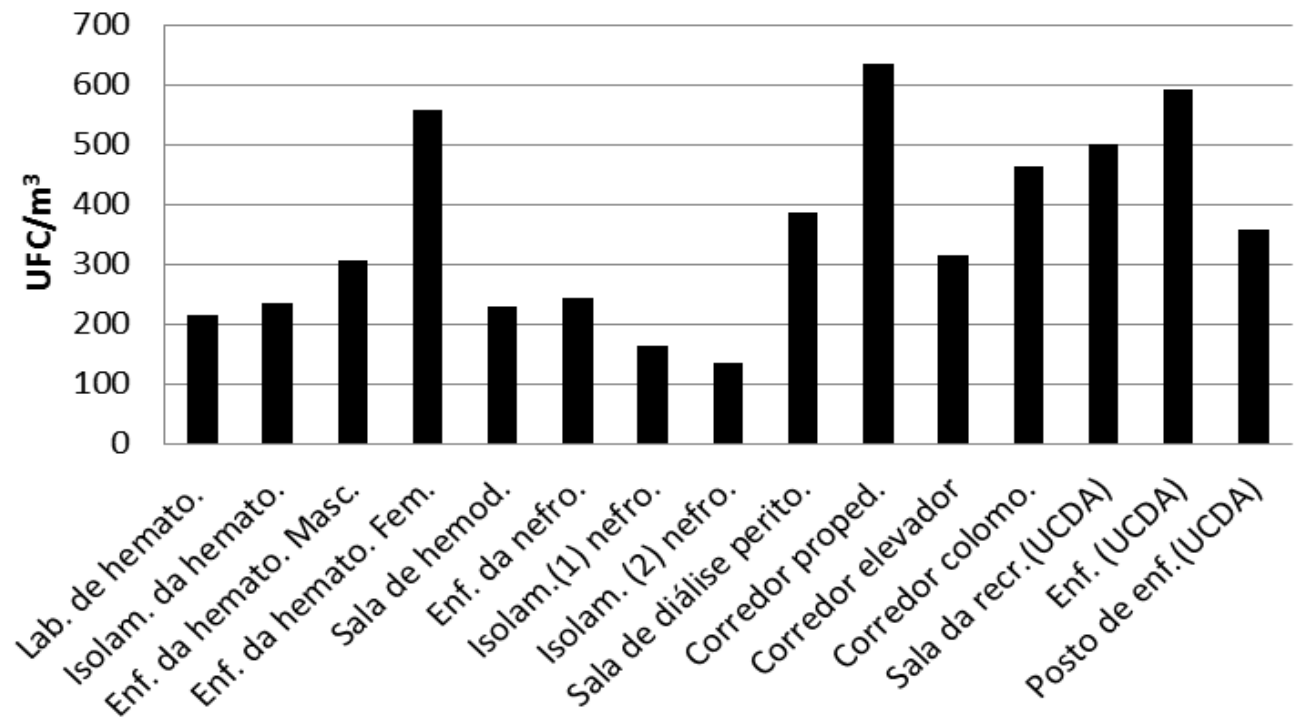


Gráfico 8 - Qualidade Microbiológica do Ar Interno das Salas do $3^{\circ}$ Pavimento do Hupe Avaliada Através da Relação do Ar Interno e Externo.

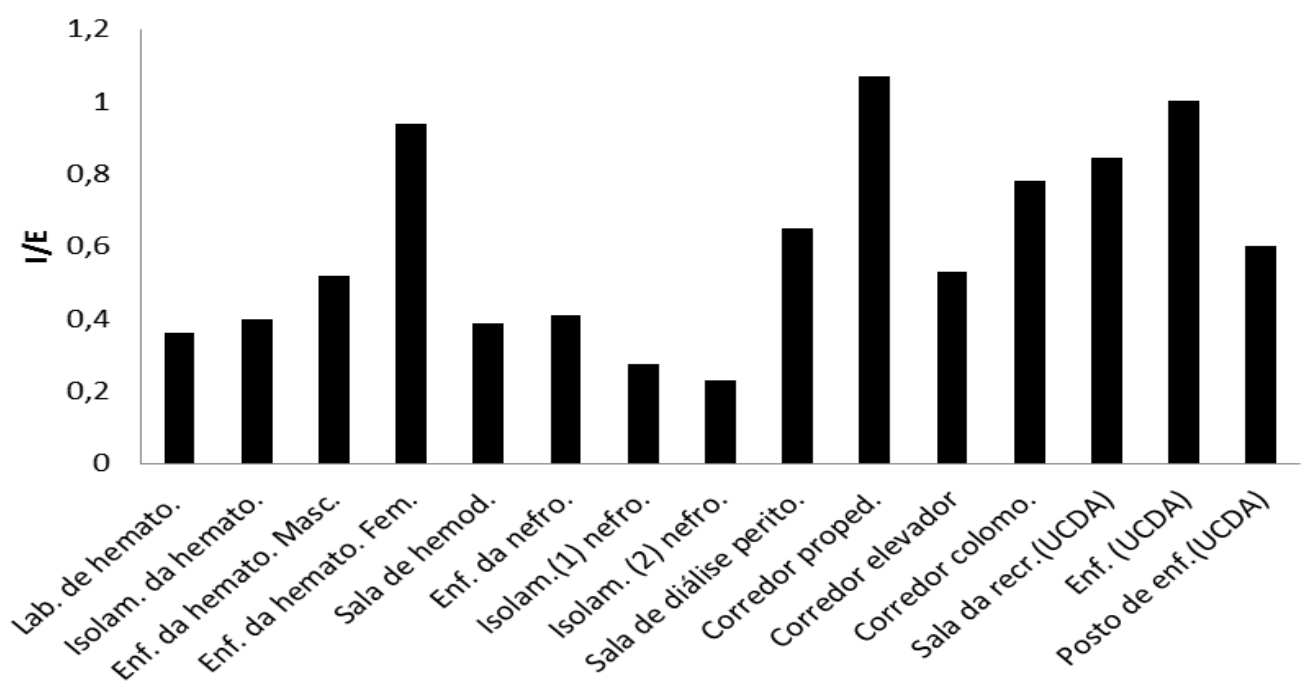

Tabela 6 - Tabela de Dados Estatísticos dos Três Pavimentos em Relação a UFC/m³.

\begin{tabular}{cccc}
\hline DADOS & \multirow{2}{*}{$1^{\circ}$ PAVIMENTO } & $2^{\circ}$ PAVIMENTO & $3^{\circ}$ PAVIMENTO \\
ESTATÍSTICOS & & 519 & 356 \\
$\bar{X}$ & 621 & 14021 & 5336 \\
$\Sigma$ & 11185 & 209108 & 25797 \\
$S^{2}$ & 822389 & 457 & 161 \\
$\mathrm{~S}$ & 907 & $88 \%$ & $45 \%$ \\
$\mathrm{CV}$ & $146 \%$ &
\end{tabular}

Gráfico 9 - Média Dos Valores De UFC/m³ Dos Três Pavimentos.

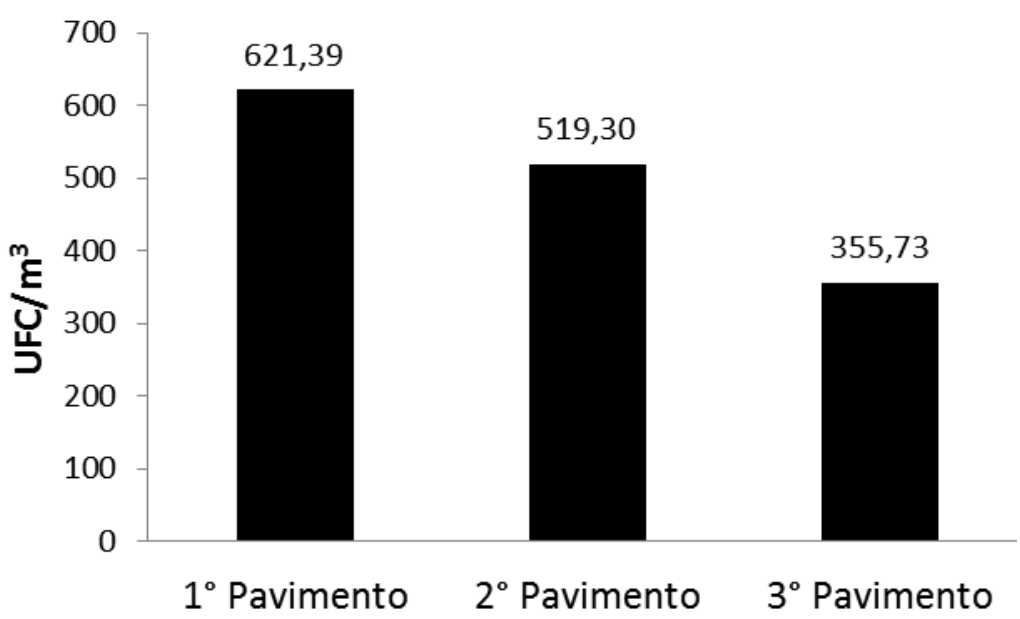


Gráfico 10 - Média Dos Valores Relativos Do Ar Interno E Externo Dos Três Pavimentos.

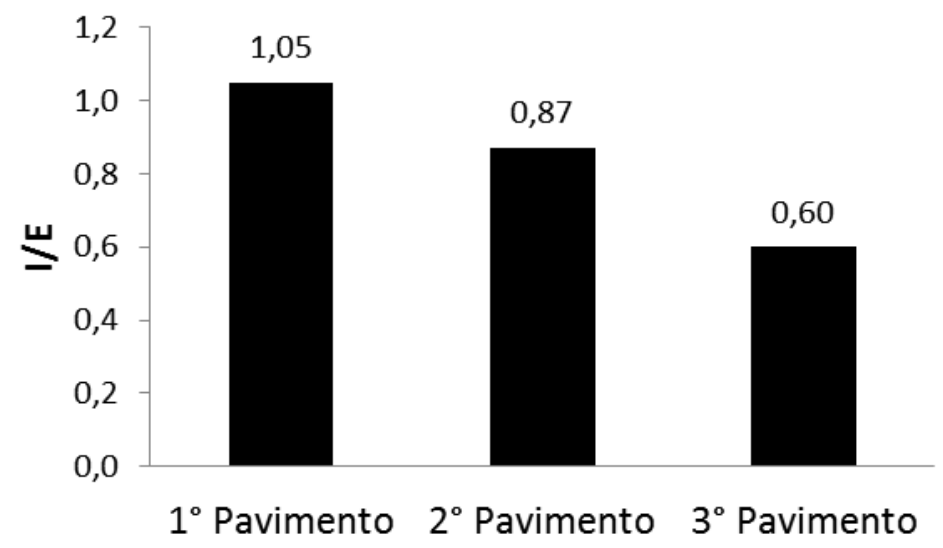

Gráfico 11 - Percentual De Locais Amostrados Acima Do Valor Máximo Aceitavel De $\mathrm{UFC} / \mathrm{m}^{3}$ Dos Três Pavimentos .

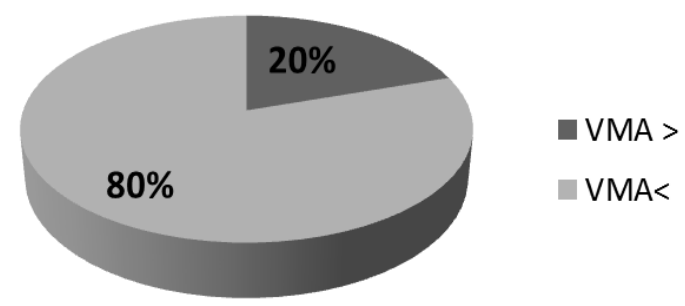

Gráfico 12 - Percentual de Locais Amostrados Acima do Valor Máximo Aceitável De I/E dos Três Pavimentos

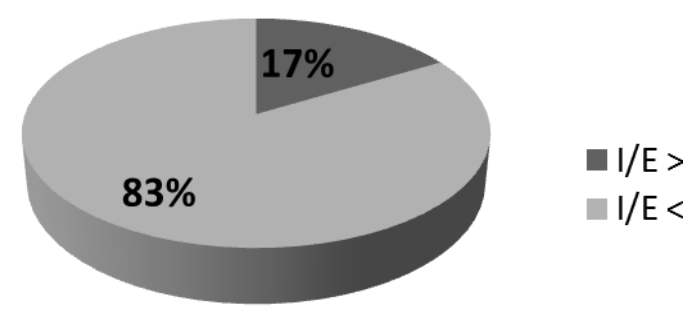




\section{DISCUSSÃO}

Os resultados permitem observar a concordância entre os dois parâmetros microbiológicos utilizados (UFC/m $\mathrm{m}^{3}$ e relação $\mathrm{I} / \mathrm{E}$ ) para a avaliação da qualidade do ar nos diversos setores do HUPE. (Tabela 3 e Gráficos 1,2 e 3). Apenas no Laboratório de Micobactéria o número de unidades formadoras de colônia por metro cúbico de ar condena a qualidade do ar, sem concordância da relação I/E. Porém observa-se que o valor I/E obtido, equivalente a 1,397, esta próximo do limite aceitável, por isso demonstra uma correlação positiva entre tais parâmetros, mostrando inteira compatibilidade dos resultados.

Vinte e oito por cento dos ambientes examinados no primeiro pavimento apresentaram má qualidade do ar revelando uma concentração de fungos acima da desejada nos seguintes locais: laboratório de imunologia, endocrinologia, e de micobactéria, o corredor próximo ao elevador e principalmente o ambulatório de quimioterapia estiveram nesta situação.

A interpretação dos resultados provenientes dos setores analisados no $1^{\circ}$ pavimento do HUPE é complexa e, certamente é de âmbito multifatorial. Observa-se que as melhores condições microbiológicas do ar interno foram obtidas no laboratório de bacteriologia, no laboratório geral, no ambulatório de neurologia e no setor de nutrição parenteral, entre outros. Embora não se possa precisar a magnitude da influência, é possível que o rigor de assepsia que deva ser tomada nestes setores, com aplicação de técnicas de antissepsia, desinfecção e esterilização seja um dos fatores responsáveis por esta condição.

Os dados observados nos setores do $2^{\circ}$ pavimento do HUPE são, inteiramente, concordantes com os do primeiro. Vinte e seis por cento dos ambientes apresentaram fungos acima de $750 \mathrm{UFC} / \mathrm{m}^{3}$ e simultaneamente, relação I/E superior a 1/5 (Tabela 4 e Gráficos 4, 5 e 6). O gráfico 6 mostra a inteira compatibilidade dos parâmetros microbiológicos aplicados. Neste pavimento, os níveis mais altos de contaminação foram obtidos e salas relacionadas com assistência respiratória, enfermagem associada à DIP e Lactário. Também podemos sugerir que as atividades desenvolvidas nestes setores possam influenciar na contaminação dos ambientes. Esta sugestão torna-se mais provável quando, se reporta aos ambientes com melhor qualidade do ar, neste pavimento. As salas de cirurgia pediátrica e de nutrição enteral requerem rigor excessivo e contínuo como medida preventiva de contaminação microbiana o que pode ter influenciado os níveis de fungos observados. 
É obvio que não só as atividades desenvolvidas em cada setor, mas também o número e o tipo de utensílios e equipamentos, o material empregado na construção e revestimento das salas, o fluxo de renovação do ar, a arquitetura e localização das salas, a temperatura e umidade do ar e o número de pessoas que habitam o ambiente são fatores que, isoladamente influenciam a qualidade do ar interior. Estes fatores atuam de forma integrada e, em cada situação, um deles pode ser mais relevante que os demais.

Observa-se que nos laboratórios de todos os pavimentos estudados, onde o número de pessoas e a circulação são frequentemente mais reduzidos, a qualidade do ar foi, em geral, melhor. Já nas enfermarias, usando o mesmo raciocínio observou-se concentração de fungos repetidamente, fora ou muito próxima, dos limites aceitáveis.

Todos os setores do $3^{\circ}$ pavimento apresentaram níveis aceitáveis de fungos, em relação aos dois parâmetros microbiológicos utilizados (Tabela 4 e Gráficos 9, 10 e 11).

Foi possível observar uma redução no número de fungos nos andares superiores. O terceiro pavimento concentra setores de isolamento e tem menor circulação de pessoas. Mesmo dentro de limiteis aceitáveis, os maiores níveis de fungos também foram observados em algumas enfermarias, corredores e setor de recreação, revelando que as atividades, desenvolvidas e a circulação de pessoas possam ser fatores importantes na qualidade do ar. A tabela 5 reforça este raciocínio ao demonstrar que os maiores níveis de fungos no ar foram encontrados em setores de isolamento de pacientes.

A qualidade do ar interno de ambientes coletivos deve ser continuamente monitorada, embora esta ainda não seja a cultura brasileira. Quando se considera os setores do hospital geral, a situação torna-se mais crítica, pois envolve maiores riscos à saúde e complexidade de medidas saneadoras.

Diversos setores nosocomiais como as enfermarias, os corredores de circulação e as salas de DIP podem ter maior prevalência de microrganismos potencialmente patogênicos devido a um número maior de pessoas e de pacientes com tipos específicos de infecções. Os resultados apresentaram uma relação direta entre quantidade de pessoas circulando entre andares e quantidade de esporos fúngicos no ar.

Os parâmetros microbiológicos legais atuais, que traduzem a qualidade do ar interior, não contemplam uma investigação mais detalhada que revele a existência de bactérias ou vírus a fim de correlacioná-los. Por isso a correspondência entre a presença de fungos no ar e 
doenças respiratórias específicas pode não indicar diretamente um nexo causal e sim apresentar de forma geral as condições ambientais relacionadas à saúde.

\section{CONCLUSÃO}

A principal revelação que emana deste trabalho é a constatação de que $28 \%$ dos setores avaliados do $1^{\circ}$ pavimento do HUPE e $26 \%$ dos contidos no $2^{\circ}$ pavimento não estão tendo a renovação de ar desejada, propiciando o acúmulo de fungos. Considerando-se que, com frequência, os ambientes com ar interno de má qualidade são aqueles onde a reposição de microrganismos pode ser prevista como contínua e mais intensa, pode sugerir que estas áreas tenham condições facilitadoras para a aquisição de certos tipos de doença, embora esta correlação só possa ser feita comparando-se os dados obtidos com outros de conhecimento da CCIH do HUPE.

Espera-se que este trabalho, muito mais do que possa revelar em termos de qualidade do ar interno do HUPE, contribua para sedimentar a cultura do monitoramento contínuo em ambientes de saúde pública.

\section{REFERÊNCIAS}

ÂNGUlO, R. J.; INFANTE, G. P.; DOMÍNGUEZ, V.; MEDIALILlA, M. A.; CARIDAD, O. Pathogenic and Antigenic Fungi in School Dust of the South of Spain. In: MUILENBERG M.; BURGE H. Aerobiology. Cap..5, p. 49-66.CRC Press, Londres, 1996.

BRASIL. ANVISA. Agência Nacional de Vigilância Sanitária. Resolução RE/ANVISA no 176, de 24 de outubro de 2000. Brasília, 2000. Disponível em

<http://www.saude.mg.gov.br/images/documentos/RES_176.pdf >. Acesso em: 30/11/2014.

BRASIL. ANVISA. Agência Nacional de Vigilância Sanitária. Resolução RE-No 9, de 16 de janeiro de 2003. Brasília, 2003. Disponível em

< http://portal.anvisa.gov.br/wps/wcm/connect/d094d3004e5f8dee981ddcd762e8a5ec/Resolucao_RE_n_09.pdf? MOD=AJPERESpdf $>$. Acesso em: 30/11/2014

ANSI/ASHRAE. Ventilation for acceptable indoor air quality. Ashrae Standard 62 - 1989. Atlanta, 1989.

BRICKUS, L.S.R.; CARDOSO, J.N.; NETO, A.F.R. Distributions of Indoor and Outdoor Air Pollutants in Rio de Janeiro, Brazil: Implications to Indoor Air Quality in Bayside Offices. Environmental. Science \& Technology. ,32, p. 3485 - 3490, Washington, 1999.

CARMO, A.; TROTA, P.; RACINE, T. A.. Qualidade do Ar interno. Texto Técnico, Escolada USP. São Paulo, 1999.

CLCDE (Centro Latinoamericano de Capacitacion y desarrollo de empresas). Soluções para Garantia de Qualidade de Ar em Sistemas de Ar Condicionado. Seminário Especial, São Paulo (2000). 
De ANDRADE, J. B.; MIGUEL, A. H. Determination of carbonyl compounds in exhaust gases from alcoholfuelled vehicles equipped with three-way catalytic converters. Inter. J. Environ. Anal.Chem., 21; p. 229-237, 1985.

LI, D. W.; KENDRICK, B. Funtional and causal relationships between indoor and outdoor airborne fungi. Can. J. Bot. 74: 194-209, 1996.

EZEONU, I. M.; PRICE, D. L.; SIMMONS, R. B.; CROW, S. A.; AHEARN, D.G. Fungal production of volatiles during growth on fiberglass. Appl. Environm. Micr. V. 60, n.11, p. 4172-4173, 1994.

EPA (ENVIRONMENTAL PROTECTION AGENCY). Indoor Air Facts $\mathbf{n}^{\circ} 4$ - Sick Building Syndrome. EPA. Washington s.d. Disponível em <.http://www.epa.gov/iaq/pubs. 1991>. Acesso no dia 29/11/14.

EPA (ENVIRONMENTAL PROTECTION AGENCY). Indoor Air Quality Facts. EPA. Washington s.d. Disponível em <http://www.epa.gov.iap/pubs. 1995>. Acesso no dia 29/11/14.

FELDMAN, K. Samplingfor airborne contaminants. Biocycle, v,36, n.8, p.84-86, 1995.

GAVA, M. A. Desempenho de Diferentes Meios de Cultura Utilizados Na Avaliação de Fungos Presentes Em Ambientes de Produção de Alimentos. 2002. 50 f. Dissertação (Mestrado em Ciências: Microbiologia Agrícola), Escola Superior de Agricultura Luiz de Queiroz, São Paulo - 2002.

GIODA, A.; NETO F. R. A. Poluição Química Relacionada ao Ar de Interiores no Brasil.Rev. Quim. Nova, 26: págs. 359-365. São Paulo, 2003.

GOUlart, E. G.; LEITE, I. C.; MORAES, R. G. Parasitologia \& Micologia Humana. $2^{\circ}$ ed. Cultura Médica: Rio de Janeiro, 1978

HANSEN, S.J. Indoor Air Quality. Fairmant Press: Lilburn, 1991.

KULCSAR, N.F.; SIQUEIRA, L. F. Padrões referenciais para análise de resultados de qualidade microbiológica em interiores visando a saúde pública no Brasil. Rev. Brasindoor, v2, n.10, p. 4-20: São Paulo, 1998.

LIGUGNANA, R.; FUNG, D. Y. C. Training of food and dairy staff for microbiological air and surface hygiene. Dairy, Food and Environmental Sanitation, v.10, n.3, p130-135: Iowa, 1990.

MACNEIL, L.; KAURI, T.; ROBERTSON, W. Molecular techniques and their potencial application in monitoring the microbiological quality of indoor air. Canad. Jour. Microb. v.41, p. 657-665: Ontario, 1995.

MINISTÉRIO DA SAÚDE. Portaria no 3523 de 28 de agosto de 1998. Brasília, 1998.

NETO, F. R. A; BRICKUS, S. L. R. Rev. Brasindoor, 3-4. São Paulo, 1999.

NIOSH (NATIONAL INSTITUTE OF OCCUPATIONAL AND SAFETY HEALTH). NIOSH Pocket guide to chemical hazards, US Gov. Printing Office: Washington 1994.

PARKER, J. The toxic zone. Buildings the CIBSE Journal, n. 15, p. 24-26, Londres, 1993.

PELCZAR, M.; REID, R.; CHAN, E. C. S. Microbiologia. McGraw-Hill: pp 1072. São Paulo,1981.

POMAlESKI. D.R.M.; MiguEL, A. H. Resumos do $14^{\circ}$ Reunião Anual da Sociedade Brasileira de Química. Caxambú, 1991.

PRÓ-ANÁliSE. Amostrador de Ar MAS 100 Merck. Cotia, 2014. Disponível em <http://www.proanalise.com.br/img/uploads/produtos/1090900001.jpg>. Acessado em 30/11/2014

RADLER, F.; NETO, A. Poluição Química Relacionada ao Ar de Interiores no Brasil. Rev. Quím. Nova, .n. 26: p. 359-365: São Paulo, 2003. 
RAW, G. Indoor Air Quality: Key sources of pollution. Buildings Services the CIBSE Journal, n. 19, p. 27-28: Londres, 1997.

ROBERTSON, G. SickBuilding - Effects, causes, analysis and prevention. In: Councill on Tall Building and Urban Habitat. Rehabilitation of Damaged Building. Le High University, p.70 - 88: Bethlehem, 1995.

SODRÉ, E. D. Estudo Preliminar da Poluição “Indoor” por Formaldeído em Prédios Públicos. Monografia (Especialização em Química Ambiental). Instituto de Química da Universidade do Estado do Rio de Janeiro, 2004.

LI T. C.; AMBUI, S.; MOHANDAS, K.; WAH M. J.; SULAIMAN' L. H.; MURGAIYAH, M. Bacterial constituents of indoor air in a high throughput building in the tropics. Tropical Biomedicine. v.31 n.3. p. 540556: Kuala Lampur, 2014.

U.S.EPA. Compendium Method TO-11A. Determination of Formaldehyde in Ambient Air Using Adsorbent Cartridge Followed by High Performance Liquid Chromatography. U.S. Gov. Washighton, s.d.

VERONESI, R. Doenças Infecciosas e Parasitárias. $7^{\mathrm{a}}$ ed. Guanabara Koogan,: Rio de Janeiro, 1982.

WMO (WORLD METEOROLOGY ORGANIZATION). 7 Million premature deaths annually linked to air pollution. Disponível em <http://www.who.int/mediacentre/news/releases/2014/air-pollution/en/> Acessado em $03 / 12 / 2014$ 